\title{
Electron Swarm Parameters in Methane-Nitrogen Mixtures
}

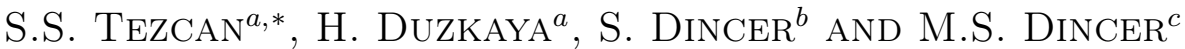 \\ ${ }^{a}$ Gazi University, Department of Electrical-Electronics Engineering, 06570, Ankara, Turkey \\ ${ }^{b}$ Ankara University, Department of Chemistry, 06100, Ankara, Turkey \\ ${ }^{c}$ Near East University, Department of Electrical-Electronics Engineering, 99138, Nicosia, Cyprus
}

(Received October 8, 2018; in final form March 7, 2019)

\begin{abstract}
In this paper, binary methane-nitrogen gas mixtures are recommended in order to reduce the industrial use of methane, which stands out among the greenhouse gases. The electron mean energy, drift velocity, ionization and effective ionization coefficients are presented for the binary mixtures with the $\mathrm{CH}_{4}$ content, varying from $20 \%$ to $80 \%$ in the mixtures. The relevant parameters of pure methane and nitrogen are evaluated for comparison with the data available in literature in order to verify the validity of the computational methodology which is based on solution of the Boltzmann equation. The swarm parameters in the methane-nitrogen mixtures have been evaluated for $E / N$ from $80 \mathrm{Td}$ to $400 \mathrm{Td}\left(1 \mathrm{Td}=1 \times 10^{-17} \mathrm{~V} \mathrm{~cm}^{2}\right)$. The presented data and the results have the potential to be widely used in plasma physics, electrical insulation systems, and space studies.
\end{abstract}

DOI: 10.12693/APhysPolA.135.495

PACS/topics: 29.40.Cs, 34.50.Fa, 34.50.Gb, 51.50.+v, 52.25.Fi, 52.25.Mq

\section{Introduction}

Methane $\left(\mathrm{CH}_{4}\right)$ is frequently used in industry applications, such as plasma processing of semiconductor surfaces, chemical vapour deposition of hard carbon and diamond, particle counters, and electron beam controlled and diffuse discharge switches [1-3]. In $\mathrm{CH}_{4}$, it is possible to achieve fast turn-on and -off current magnitudes in discharge switching applications [4]. In electron beam controlled switches when the beam is on, large electron production rate is required and this is achieved by ionization collisions resulting in conduction and current flow. However, when the e-beam is turned off, electron and ion densities in the switch decay due to recombination and attachment resulting in increased resistance by orders of magnitude causing current interruption and the switch returns turn off position. However, $\mathrm{CH}_{4}$ is an important greenhouse gas together with $\mathrm{CO}_{2}$ and water vapour which are the important greenhouse effect contributors [5].

The use of $\mathrm{CH}_{4}$ is restricted to the Kyoto protocol [6]. Despite this restriction, the concentration of methane in the atmosphere is constantly increasing in the postindustrial period. The changes in the atmospheric concentration of methane and global surface temperature relative to 1951-1980 average temperatures after 1950 are given in Table I [7, 8].

Nitrogen is one of the important alternatives for the use of greenhouse gases in the gaseous electronics and plasma processing industry due to its inherent advantages, such as sufficient level of insulation strength, nonflammability, non-toxic, and less cost $[9,10]$. The application of $\mathrm{N}_{2}$ based plasma and gas-insulated equipment

*corresponding author; e-mail: stezcan@gazi.edu.tr
TABLE I

Atmospheric concentrations of methane (parts per billion, ppb) and global surface temperature relative to 1951-1980 average temperatures.

\begin{tabular}{c|c|c|c|c|c}
\hline \hline Year & $\begin{array}{c}\text { Value } \\
{[\mathrm{ppb}]}\end{array}$ & $\begin{array}{c}\text { Temp. } \\
{\left[{ }^{\circ} \mathrm{C}\right]}\end{array}$ & Year & $\begin{array}{r}\text { Value } \\
{[\mathrm{ppb}]}\end{array}$ & $\begin{array}{c}\text { Temp. } \\
{\left[{ }^{\circ} \mathrm{C}\right]}\end{array}$ \\
\hline 1950 & 1161.7 & -0.19 & 1985 & 1652.3 & 0.12 \\
1955 & 1207.0 & -0.14 & 1990 & 1709.3 & 0.44 \\
1960 & 1263.0 & -0.02 & 1995 & 1747.1 & 0.44 \\
1965 & 1328.5 & -0.10 & 2000 & 1774.5 & 0.40 \\
1970 & 1403.2 & 0.03 & 2005 & 1774.7 & 0.67 \\
1975 & 1483.6 & -0.02 & 2010 & 1796.9 & 0.70 \\
1980 & 1566.3 & 0.27 & 2015 & 1834.8 & 0.86
\end{tabular}

TABLE II

Physical and environmental properties of $\mathrm{CH}_{4}$ and $\mathrm{N}_{2}$.

\begin{tabular}{l|c|c}
\hline \multicolumn{1}{c|}{ Properties } & $\mathrm{CH}_{4}$ & $\mathrm{~N}_{2}$ \\
\hline molecular weight $[\mathrm{g} / \mathrm{mol}]$ & 16.04 & 28.01 \\
density $[\mathrm{g} / \mathrm{L}]$ & 0.72 & 1.25 \\
boiling point $\left[{ }^{\circ} \mathrm{C}\right]$ & -161.5 & -196 \\
$\mathrm{GWP}^{a}$ for 100 year time horizon & 23 & - \\
atmospheric lifetime $[\mathrm{y}]$ & $8.4 / 12$ & $1.610^{7}$ \\
flammability & yes & no \\
toxicity & no & no \\
breakdown voltage $[\mathrm{kV} /(\mathrm{cm}$ bar $)]$ & 21.5 & 32.9 \\
\hline
\end{tabular}

${ }^{a}$ global warming potential.

technologies can be found in high voltage devices, diffuse discharge switches, exhaust gas pollution control, plasma etching, decontamination and surface treatment industries $[11,12]$. Some physical and environmental properties of $\mathrm{CH}_{4}$ and $\mathrm{N}_{2}$ are shown in Table II [13-15].

Among the alternative gas mixtures to $\mathrm{CH}_{4}$, binary gas mixtures of $\mathrm{CH}_{4}-\mathrm{N}_{2}$ are considered to be one of the most possible candidates to be used in reality, because 
$\mathrm{N}_{2}$ has no greenhouse effect and relatively low cost [16]. However, it is very important to understand the electron swarm data and insulation characteristics with a reduced $\mathrm{CH}_{4}$ content in this recommended gas mixture.

Electron swarm data, such as mean energy, drift velocity, and effective ionization coefficients are required to understand and predict the behaviour in various industrial applications. These applications include plasma processing for semiconductor surfaces, pollution control, and diffusion of discharge switches and electrical insulators $[17,18]$. Besides these applications, $\mathrm{CH}_{4}$ and $\mathrm{N}_{2}$ are one of the most abundant components of the atmospheres of the earth, outer planets and satellites. For example, $\mathrm{CH}_{4}$ and $\mathrm{N}_{2}$ are the most commonly encountered gases in the Triton and Titan moons of Neptune and Saturn, respectively [3, 12]. Therefore, electron swarm data in $\mathrm{CH}_{4}$ and $\mathrm{N}_{2}$ gases also play a fundamental role in ionospheric and atmospheric phenomena in the space research [19].

The aim of this study is to report on the calculation of the mean energy, drift velocity, and effective ionization coefficients using the Boltzmann equations for the binary $\mathrm{CH}_{4}-\mathrm{N}_{2}$ gas mixtures at different concentrations and over a large reduced electric field $E / N$ range. Electron swarm data are generally available in the literature for the pure $\mathrm{CH}_{4}$ and $\mathrm{N}_{2}$ gases, but the data in the $\mathrm{CH}_{4}-$ $\mathrm{N}_{2}$ gas mixtures are limited [20].

\section{Computational methodology}

The electron swarm parameters of pure $\mathrm{CH}_{4}, \mathrm{~N}_{2}$, and binary mixtures of these gases are obtained by the Boltzmann equation method. The Boltzmann equation is solved with steady state Townsend theory approach by using electron cross-sections of these gases. As a result of this solution, electron energy distribution functions of these gases are obtained. The Boltzmann equation method is described in detail in [21, 22]. The explicit formation of this equation reads as follows:

$$
\begin{aligned}
& \left(\frac{E}{N}\right)^{2} \frac{\mathrm{d}}{\mathrm{d} \varepsilon}\left(\frac{\varepsilon}{3 Q_{T}} \frac{\mathrm{d} f}{\mathrm{~d} \varepsilon}\right)+\left(\frac{e E}{N}\right)\left(\frac{\alpha-\eta}{N}\right) \frac{\mathrm{d}}{\mathrm{d} \varepsilon}\left(\frac{\varepsilon}{3 Q_{T}} f\right) \\
& +\left(\frac{e E}{N}\right)\left(\frac{\alpha-\eta}{N}\right) \frac{\varepsilon}{3 Q_{T}} \frac{\mathrm{d} f}{\mathrm{~d} \varepsilon}+\left(\frac{\alpha-\eta}{N}\right)^{2} \frac{\varepsilon}{3 Q_{T}} f \\
& +\frac{2 m}{M} \frac{\mathrm{d}}{\mathrm{d} \varepsilon}\left(\varepsilon^{2} Q_{m} f\right)+\left(\varepsilon+\varepsilon_{\nu}\right) Q_{\nu}\left(\varepsilon+\varepsilon_{\nu}\right) f\left(\varepsilon+\varepsilon_{\nu}\right) \\
& -\varepsilon Q_{\nu}(\varepsilon) f(\varepsilon)+\left(\varepsilon+\varepsilon_{e x}\right) Q_{e x}\left(\varepsilon+\varepsilon_{e x}\right) f\left(\varepsilon+\varepsilon_{e x}\right) \\
& -\varepsilon Q_{e x}(\varepsilon) f(\varepsilon)+2\left(2 \varepsilon+\varepsilon_{i}\right) Q_{i}\left(2 \varepsilon+\varepsilon_{i}\right) f\left(2 \varepsilon+\varepsilon_{i}\right) \\
& +2\left(2 \varepsilon+\varepsilon_{i}\right) Q_{i}\left(2 \varepsilon+\varepsilon_{i}\right) f\left(2 \varepsilon+\varepsilon_{i}\right) \\
& -\varepsilon Q_{i}(\varepsilon) f(\varepsilon)-\varepsilon Q_{a}(\varepsilon) f(\varepsilon)=0,
\end{aligned}
$$

where $E$ and $N$ are applied electric field intensity and gas density, $e$ and $m$ are the charge and mass of electron, $M$ and $f$ are molecular mass and electron energy distribution function, $\alpha$ and $\eta$ are Townsend's first ionization and attachment coefficients, $\varepsilon$ is kinetic energy of an electron, $\varepsilon_{v}, \varepsilon_{e x}$ and $\varepsilon_{i}$ are threshold energy of vibrational, excitation and ionization cross-sections, respectively. Also, in Eq. (1), $Q_{m}, Q_{v}, Q_{e x}, Q_{i}$ and $Q_{a}$ are the electron crosssections for momentum, vibrational excitation, electronic excitation, ionization and attachment, respectively. $Q_{T}$ is an effective cross-section, which is obtained by collecting the electron cross-sections of each gas or binary gas mixtures, defined as:

$$
\begin{aligned}
& Q_{T_{C_{H}}}= \\
& \quad Q_{m_{C H_{4}}}+Q_{v_{C H_{4}}}+Q_{{\text {dissoc } \mathrm{C}_{4}}}+Q_{i_{C H_{4}}}+Q_{a_{C H_{4}}} \\
& Q_{T_{N_{2}}}=Q_{m_{N_{2}}}+Q_{v_{N_{2}}}+Q_{e_{x_{N_{2}}}}+Q_{T_{i_{N_{2}}}} \\
& Q_{T}=k Q_{T_{C_{4}}}+(1-k) Q_{T_{N_{2}}}
\end{aligned}
$$

$Q_{\text {dissoc }}$ is dissociation cross-section. In Eq. (4), $k$ denotes the ratio of $\mathrm{CH}_{4}$ in the binary gas mixtures.

An iterative process is initiated by assigning a guess value of effective ionization coefficient, $\alpha-\eta$ (for $\mathrm{N}_{2}$, $\eta=0$ ), and after this process the electron energy distribution function, $f(\varepsilon)$, is obtained [22]. By using this distribution function, electron swarm parameters, such as electron mean energy, electron drift velocity, and effective ionization coefficient are obtained as follows:

$$
\begin{aligned}
& \epsilon=\int_{0}^{\infty} \sqrt{\varepsilon^{3}} f(\varepsilon) \mathrm{d} \varepsilon \\
& W=-\frac{e E}{3 N} \sqrt{\frac{2}{m}} \int_{0}^{\infty} \frac{\varepsilon}{Q_{T}(\varepsilon)} \frac{\mathrm{d} f(\varepsilon)}{\mathrm{d} \varepsilon} \mathrm{d} \varepsilon \\
& \frac{\alpha-\eta}{N}=\frac{1}{W} \sqrt{\frac{2 e}{m}} \int_{0}^{\infty} \varepsilon\left(Q_{i}(\varepsilon)-Q_{a}(\varepsilon)\right) f(\varepsilon) \mathrm{d}(\varepsilon) .
\end{aligned}
$$

The electron cross-sections for $\mathrm{CH}_{4}$ and $\mathrm{N}_{2}$ are taken from [1] and [23], respectively. The threshold energies of vibrational, dissociation, ionization, and attachment cross-section for $\mathrm{CH}_{4}$ are 0.16, 9.0, 12.6, and $7.7 \mathrm{eV}$ and threshold energies of vibrational, excitation and ionization cross-section for $\mathrm{N}_{2}$ are $0.29,6.17$, and $15.6 \mathrm{eV}$, respectively $[1,23]$.

\section{Results and discussions}

The electron mean energy, drift velocity, ionization, and effective ionization coefficient in pure $\mathrm{CH}_{4}$, pure $\mathrm{N}_{2}$, and their binary mixtures are calculated using the Boltzmann equation analysis in the interval of $80 \mathrm{Td}$ to $400 \mathrm{Td}$ since our interest is to analyse the swarm parameters above the limiting $E / N$ value of $\mathrm{CH}_{4}$ which is in the vicinity of $87 \mathrm{Td}[1,15]$.

The electron mean energy of pure $\mathrm{CH}_{4}$ is shown in Fig. 1. The calculated electron mean energy is compared with the results of Maric et al. [24] and good agreement is obtained.

Figure 2 displays the electron drift velocity of pure $\mathrm{CH}_{4}$. The calculated drift velocity of pure $\mathrm{CH}_{4}$ is compared with the calculated values of Song et al. [3], and the 


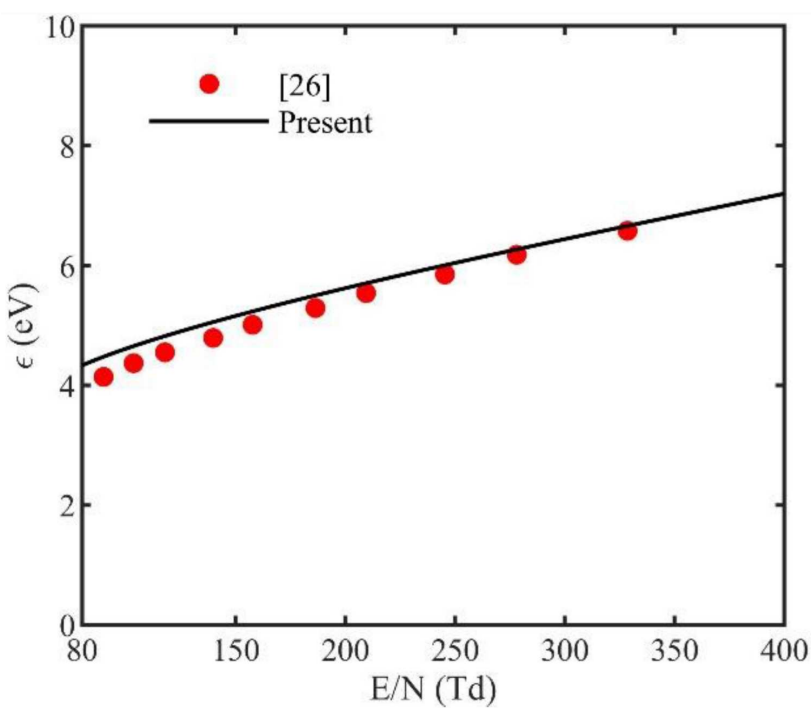

Fig. 1. Electron mean energy in $\mathrm{CH}_{4}$.

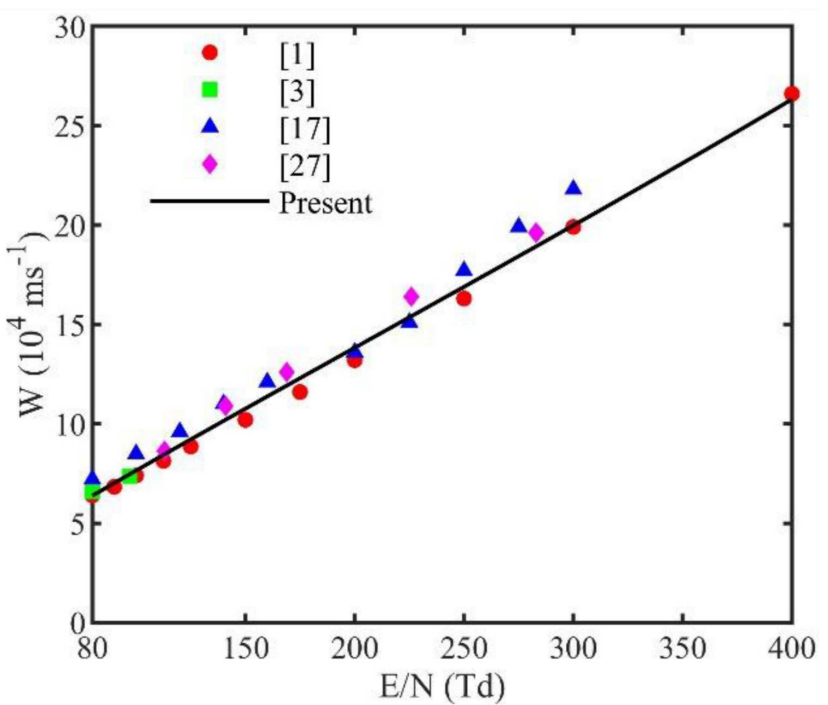

Fig. 2. Electron drift velocity in $\mathrm{CH}_{4}$.

experimental values of Davies et al. [1], Hunter et al. [15] and Al-Amin et al. [25], and reasonable agreement is found.

The reduced effective ionization coefficient in pure $\mathrm{CH}_{4}$ is shown in Fig. 3. The calculated reduced effective ionization coefficient is compared with measured ones in the literature $[2,15,26]$. The present calculations agree very well with the measured values.

The electron mean energy in nitrogen is shown in Fig. 4. Present result is compared with the Boltzmann solution [27] and with the Monte Carlo method solutions in the literature $[10,12,28,29]$. The electron mean energy increases as the reduced electric field increases.

The electron drift velocity in nitrogen is presented in Fig. 5. The drift velocity is increasing as the reduced electrical field increases. The calculated results are compatible with the measured [30] and Monte Carlo results $[10,31]$.

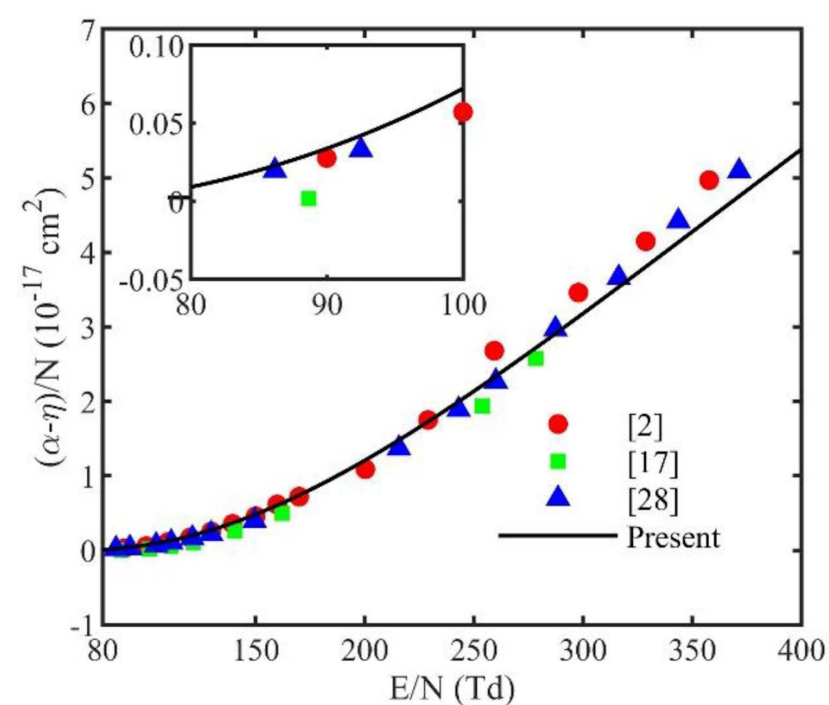

Fig. 3. Reduced effective ionization coefficient in $\mathrm{CH}_{4}$.

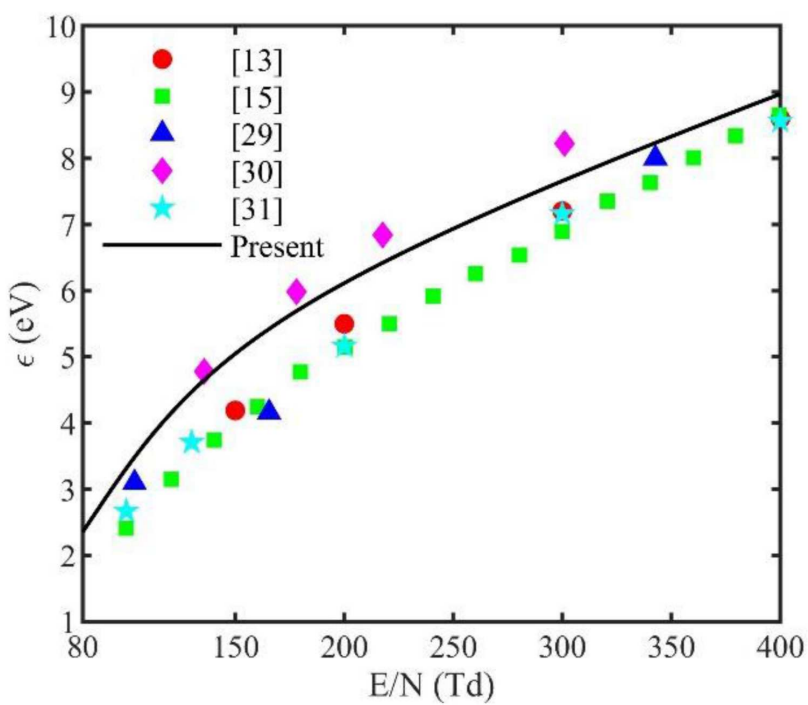

Fig. 4. Electron mean energy in $\mathrm{N}_{2}$.

The reduced effective ionization coefficient in pure nitrogen is shown in Fig. 6. The calculated results of the present study agree with the results of Dincer et al. [10], Yousfi et al. [11], Haydon and Williams [32], Kondo et al. [33], and Juarez et al. [34].

The electron mean energy in binary mixtures of $\mathrm{CH}_{4}$ and $\mathrm{N}_{2}$ is shown in Fig. 7. At low reduced electrical field values, by increasing the $\mathrm{N}_{2}$ content, the electron mean energy decreases. However, in the higher $E / N$ range above about $200 \mathrm{Td}$ it is observed that with the addition of the $\mathrm{N}_{2}$ component the response is reversed. This fact can be explained through the electron energy distribution functions. It can be observed from the energy distribution functions given in Fig. 8 that for $E / N$ lower than $200 \mathrm{Td}$, the electron population at lower energies increases with the addition of $\mathrm{N}_{2}$ in the binary mixture, while at high energies, reduction in the higher energy population is observed. However, above $200 \mathrm{Td}$ 


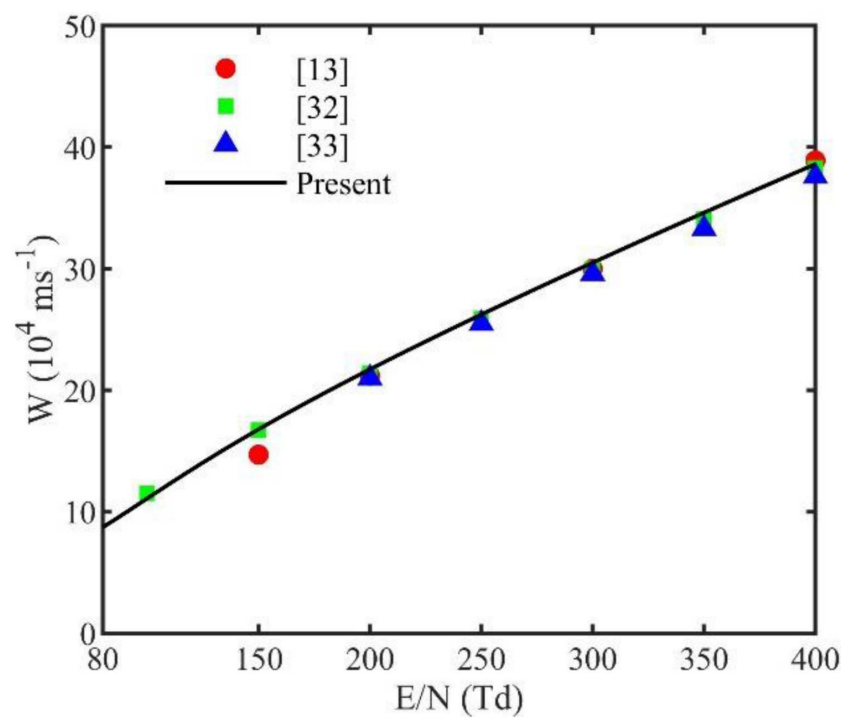

Fig. 5. Electron drift velocity in $\mathrm{N}_{2}$.

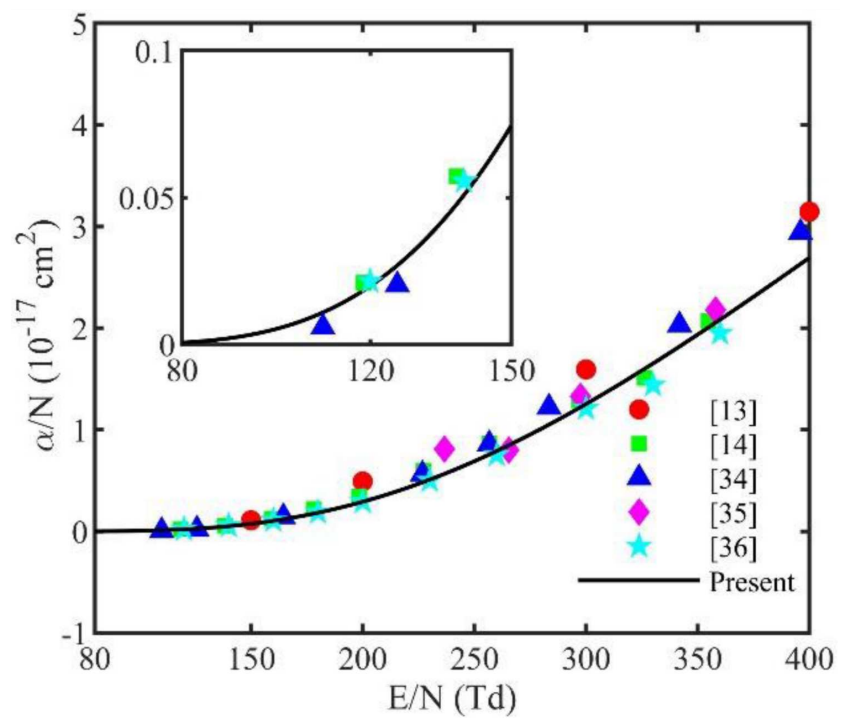

Fig. 6. Reduced ionization coefficient in $\mathrm{N}_{2}$.

the tendency is reversed with the addition of $\mathrm{N}_{2}$. Figure 9 displays electron energy distribution functions in the binary mixture at $400 \mathrm{Td}$. In Fig. 9, the same colours are used for the same mixture ratios as in Fig. 8. The energy distributions shown in this figure clearly indicate that low energy electrons are depopulated, and with the addition of $\mathrm{N}_{2}$, in the higher energy range, higher energy electrons are populated.

The electron drift velocity in $\mathrm{CH}_{4}-\mathrm{N}_{2}$ mixtures is shown in Fig. 10. The calculated values in $80 \% \mathrm{~N}_{2}$ mixture are compared with the available theoretical simulation results of Kohn et al. [20], given in the interval from $80 \mathrm{Td}$ to $160 \mathrm{Td}$ for the same mixture with good agreement. The drift velocity at a given $E / N$ increases with the addition of $\mathrm{N}_{2}$ in the binary mixture and the effect is more pronounced for higher $E / N$ values.

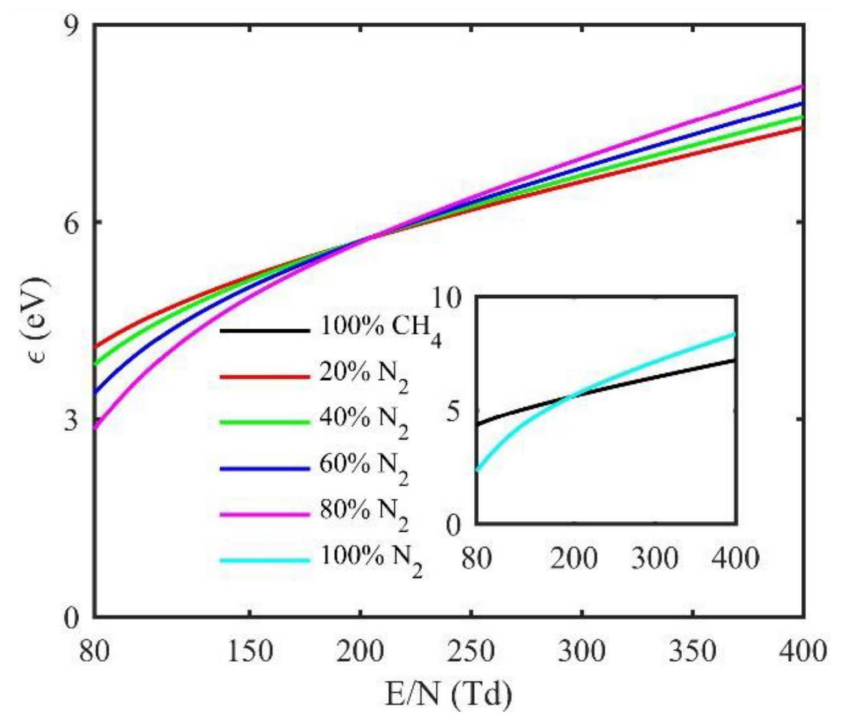

Fig. 7. Electron mean energy in $\mathrm{CH}_{4}-\mathrm{N}_{2}$ mixtures.

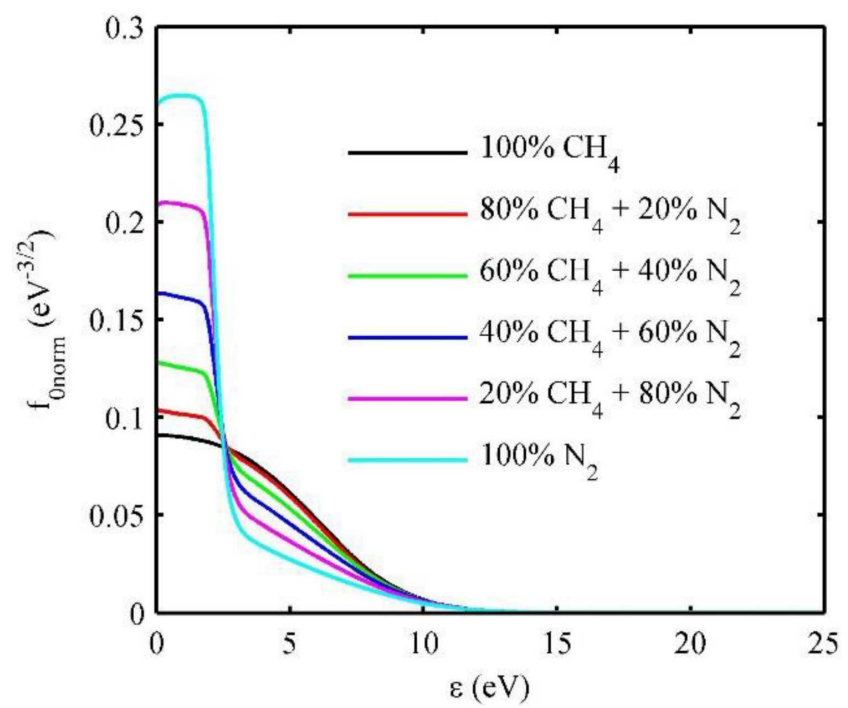

Fig. 8. Electron energy distribution functions in $\mathrm{CH}_{4}$ $\mathrm{N}_{2}$ mixtures at $100 \mathrm{Td}$.

Figure 11 displays the reduced effective ionization coefficients in $\mathrm{CH}_{4}-\mathrm{N}_{2}$ mixtures. The inset in the figure gives the Monte Carlo simulation results of Kohn et al. [20] in $80 \% \mathrm{~N}_{2}$ mixture in the given $E / N$ interval together with the results of BOSIG+ [35]. The present calculations agree with Hagelaar and Pitchford [35], since both of the calculations are carried out with two-term Boltzmann analysis. However, simulation results of the effective ionization coefficients calculated in [20] are about $19 \%$ higher at $160 \mathrm{Td}$. The difference in effective ionization coefficients with the simulation results can be due to the different collision cross-section sets adopted in the calculations and furthermore two-term limitation is not present in the Monte-Carlo simulation. It can be seen 


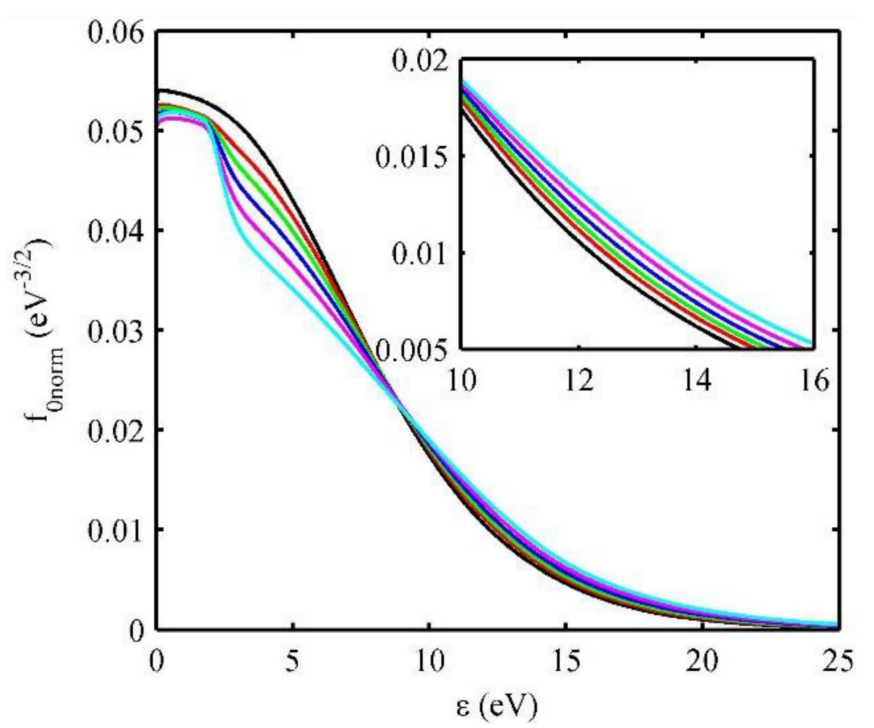

Fig. 9. Electron energy distribution functions in $\mathrm{CH}_{4}-$ $\mathrm{N}_{2}$ mixtures at $400 \mathrm{Td}$.

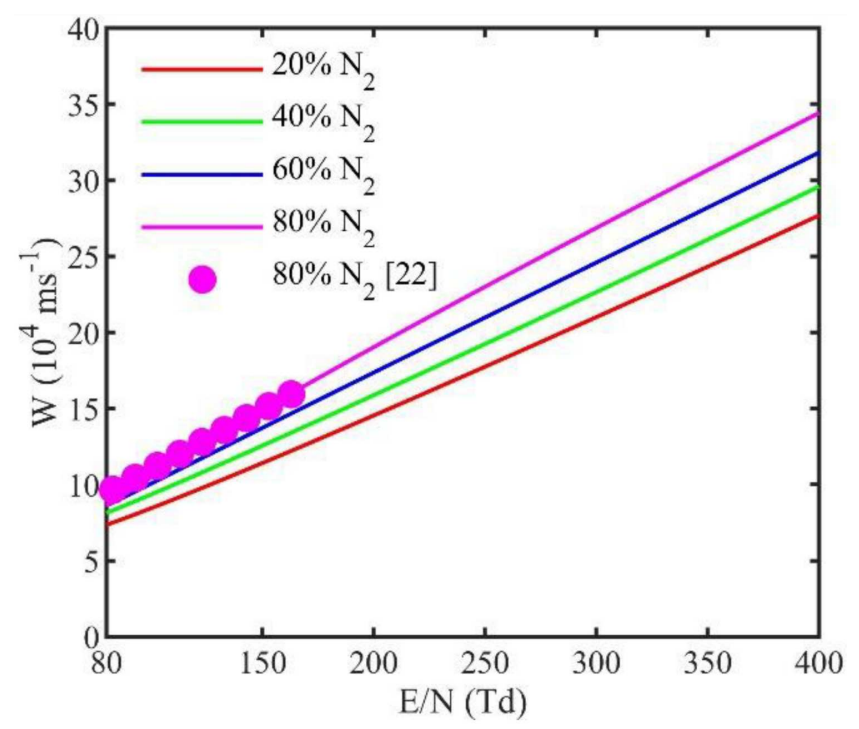

Fig. 10. Electron drift velocity in $\mathrm{CH}_{4}-\mathrm{N}_{2}$ mixtures.

from this figure, as the $\mathrm{N}_{2}$ content increases, the reduced effective ionization coefficient decreases at a given $E / N$, and the effect is more pronounced for higher $E / N$ values. The reduced effective ionization coefficient is calculated by the difference between the reduced ionization coefficient and the reduced attachment coefficient. Although $\mathrm{CH}_{4}$ is electronegative, the attachment collision frequency is not significant when compared with the ionization collision frequency of $\mathrm{CH}_{4}$ in the $E / N$ range of the present paper. Hence, the effective ionization coefficient is mostly governed by ionization collisions in $\mathrm{CH}_{4}$ and $\mathrm{N}_{2}$ in the binary mixtures. Furthermore, the peak of the magnitude of the ionization collision cross-section in $\mathrm{N}_{2}$ is quite small when compared with the magnitude of

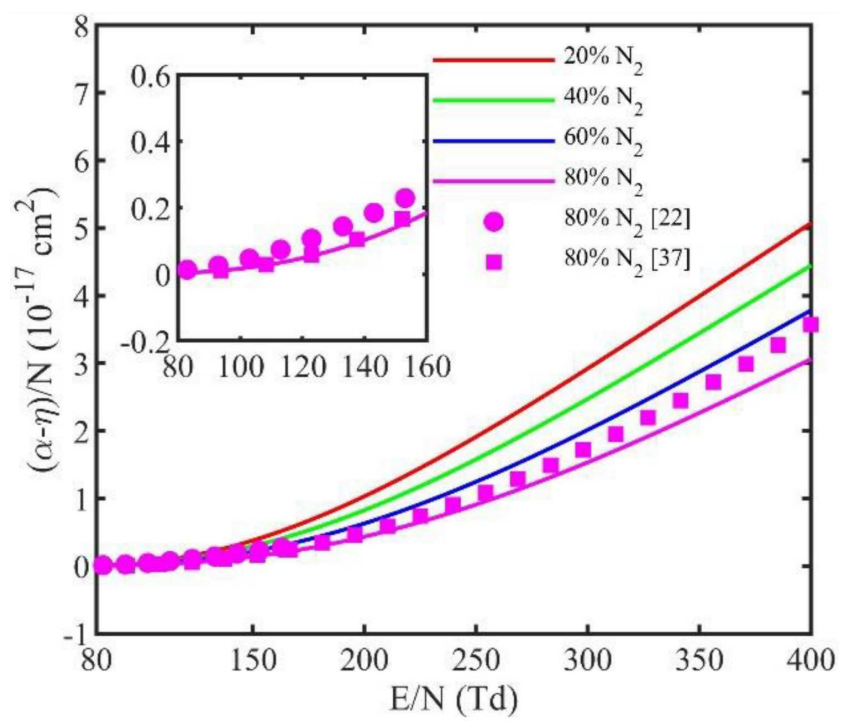

Fig. 11. Reduced effective ionization coefficient in $\mathrm{CH}_{4}-\mathrm{N}_{2}$ mixtures.

$\mathrm{CH}_{4}$ at the same electron energy. Therefore, with the increased content of $\mathrm{N}_{2}$ in the binary mixtures, depending on the mixture ratio, the effective ionization coefficient decreases as expected.

\section{Conclusions}

Employing Boltzmann's equation analysis with the code developed by the authors, the ionization and effective ionization coefficients, electron drift velocities, and mean energies are evaluated in $\mathrm{CH}_{4}+\mathrm{N}_{2}$ mixture for $\mathrm{CH}_{4}$ contends varying from 20 to $80 \%$ over a range of $E / N$, from 80 to $400 \mathrm{Td}$.

As the nitrogen content increases, the reduced effective ionization coefficient decreases at a given $E / N$. Depending on the mixture ratio, the reduction in the effective ionization coefficient is more pronounced at higher $E / N$ values.

Furthermore, it is possible to control the electron mean energy in the binary mixture with the addition of the $\mathrm{N}_{2}$ content since the electron energy distribution functions displayed at a given $E / N$ indicate the control in the number of slow electrons, and the number of higher energy electrons with the addition of $\mathrm{N}_{2}$ content in the $E / N$ range of the present paper.

\section{References}

[1] D.K. Davies, L.E. Kline, W.E. Bies, J. Appl. Phys. 65, 3311 (1989).

[2] J. de Urquijo, I. Alvarez, E. Basurto, C. Cisneros, J. Phys. D Appl. Phys. 32, 1646 (1999).

[3] M.Y. Song, J.S. Yoon, H. Cho, Y. Itikawa, G.P. Karwasz, V. Kokouline, Y. Nakamura, J. Tennyson, J. Phys. Chem. Ref. Data 44, 023101 (2015). 
[4] Y. Ohmori, K. Kitamori, M. Shimozuma, H. Tagashira, J. Phys. D Appl. Phys. 19, 437 (1986).

[5] A.V.E. Ollila, Energy Environm. 23, 781 (2012).

[6] UN, Kyoto Protocol to the United Nations Framework Convention on Climate Change, Kyoto, Japan 1998.

[7] European Environmental Agency (EAA), Atmospheric Greenhouse Gas Concentrations, 2018.

[8] NASA, Global Climate Change: Vital Signs of the Planet, 2018.

[9] M.S. Dincer, O.C. Ozerdem, S. Bektas, IEEE Trans. Plasma Sci. 35, 1210 (2007).

[10] M.S. Dincer, S.S. Tezcan, H. Duzkaya, AIP Adv. 8, 095026 (2018).

[11] M. Yousfi, J.de Urquijo, A. Juarez, E. Basurto, J.L. Hernandez-Avila, IEEE Trans. Plasma Sci. 37, 764 (2009).

[12] M. Vojnovic, M. Popovic, M.M. Ristic, M.D. Vicic, G.B. Poparic, Chem. Phys. 463, 38 (2015).

[13] E.J. Dlugokencky, E.G. Nisbet, R. Fisher, D. Lowry, Philos. Trans. R. Soc. A 369, 2058 (2011).

[14] A. Beroual, A. Haddad, Energies 10, 1216 (2017).

[15] S.R. Hunter, J.G. Carter, L.G. Christophorou, J. Appl. Phys. 60, 24 (1986).

[16] H. Okubo, T. Yamada, K. Hatta, N. Hayakawa, S. Yuasa, S. Okabe, J. Phys. D Appl. Phys. 35 2760 (2002).

[17] P. Haeflinger, C.M. Franck, Rev. Sci. Instrum. 89 , 023114 (2018).

[18] D.A. Dahl, T.H. Teich, C.M. Franck, J. Phys. D Appl. Phys. 45, 485201 (2012).

[19] Y. Itikawa, J. Phys. Chem. Ref. Data 35, 31 (2006).

[20] C. Kohn, S. Dujko, O. Chanrion, T. Neubert, arXiv:1802.09906v1 (2018).
[21] M.J. Pinheiro, J. Loureiro, J. Phys. D Appl. Phys. 35, 3077 (2002).

[22] S.S. Tezcan, M.A. Akcayol, O.C. Ozerdem, M.S. Dincer, IEEE Trans. Plasma Sci. 38, 2332 (2010).

[23] Triniti datebase, www.lxcat.net/TRINITI, retrieved on October 24, 2018.

[24] D. Maric, M. Radmilovic-Radenovic, Z.Lj. Petrovic, Eur. Phys. J. D 35, 313 (2005).

[25] S.A.J. Al-Amin, H.N. Kucukarpaci, J. Lucas, J. Phys. D Appl. Phys. 18, 1781 (1985).

[26] A.E.D. Heylen, Int. J. Electron. 39, 653 (1975).

[27] Y. Ohmori, M. Shimozuma, H. Tagashira, J. Phys. D Appl. Phys. 21, 724 (1988).

[28] G.R.G. Raju, M.S. Dincer, IEEE Trans. Plasma Sci. 18, 819 (1990).

[29] J. Liu, G.R.G. Raju, IEEE Trans. Electr. Insulat. 28, 154 (1993).

[30] H. Hasegawa, H. Date, Y. Ohmori, P.L.G. Ventzek, M. Shimozuma, H. Tagashira, J. Phys. D Appl. Phys. 31, 737 (1998).

[31] M. Janda, V. Martisovits, M. Morvova, Z. Machala, K. Hensel, Eur. Phys. J. D 45, 309 (2007).

[32] S.C. Haydon, O.M. Williams, J. Phys. D Appl. Phys. 9, 523 (1976)

[33] Y. Kondo, Y. Sekiya, M.Th. El-Mohandes, Int. J. Emerging Tech. Adv. Eng. 3, 309 (2013).

[34] A. Juarez, M. Yousfi, E. Basurto, A. Bekstein, J.L. Hernandez-Avila, M. Benhenni, J. de Urquijo, O. Eichwald, in: Proc. 28th Int. Conf. on Phenomena in Ionized Gases ICPIG, Prague (Czech Republic), 2007, p. 192.

[35] G.J.M. Hagelaar, L.C. Pitchford, Plasma Sources Sci. Technol. 14, 722 (2005). 